\title{
Intraoperative Cardiac Injury
}

National Cancer Institute

\section{Source}

National Cancer Institute. Intraoperative Cardiac Injury. NCI Thesaurus. Code C78377.

Damage to the heart during a surgical procedure. 